\title{
0 caminho do olhar: entre as pinturas e as vinhetas de televisão
}

Felipe Muanis ${ }^{1}$

UFF

1. Doutor em Comunicação Social pela UFMG (Universidade Federal de Minas Gerais) e professor adjunto do Departamento de Cinema e Vídeo da UFF (Universidade Federal Fluminense). 


\section{Resumo}

A imagem do cinema tem uma forte relação com a pintura. A televisão, todavia, costuma ser esquecida nessas discussões. $\mathrm{O}$ artigo ora apresentado relaciona pinturas e vinhetas institucionais da Rede Globo de Televisão e da MTV, para buscar similaridades nas estratégias de composição da imagem. Em diálogo com a teoria do visível proposta por Oliver Fahle, busca-se inserir a imagem televisiva em um contexto mais amplo das teorias da imagem.

\section{Palavras-chave}

vinheta, visível, eixo Z, observador, profundidade

\section{Abstract}

The image from cinema has a strong relation with painting. However, the television seems to be forgotten in these discussions. This paper relates paintings with Rede Globo's and MTV's artbreaks to look for similarities in their image composition strategies. In dialogue with Oliver Fahle's visible theory, we try to insert television image in a wide context of image theories.

\section{Key-words}

artbreaks, visible, $\mathrm{Z}$ axis, observer, depth 
Têm sido frequentes as análises e as comparações entre cinema e pintura. Desde o movimento das vanguardas de 1920 até videoartistas e acadêmicos nos dias de hoje, autores e artistas têm trabalhado a aproximação entre essas duas formas de arte. A imagem do cinema não a recusa; pelo contrário, muitos filmes reforçam explicitamente sua ligação com os modelos de pintura clássica e moderna. Estas, por sua vez, parecem encontrar no cinema seu mais disciplinado discípulo: é senso comum que o conceito de fotografia de inúmeros filmes é tributário de pinturas, especialmente barrocas, nas quais a iluminação tem uma função protagonista.

Por outro lado, a televisão também é um espaço que pode ser relacionado à pintura, ainda que detenha um sistema fordista de produção que resulta muitas vezes em uma imagem de "intensidade-zero" - para usar o conceito de Caldwell - , afastando-se de qualquer aproximação artística que se conecte com os cânones da pintura. É importante perceber, contudo, que a televisão é audiovisual e, como tal, é parte integrante de uma teoria mais ampla da imagem.

É possível, também, especialmente sobre as populares vinhetas institucionais da MTV produzidas entre 1990 e 2000, observar uma influência na própria imagem que constitui a televisão e sua transformação. Se a montagem é uma característica da arte, conforme afirma Modesto Carone (1974, p. 106-107), parece que o processo histórico da pós-modernidade a potencializa como estética. Seria então o que possibilitaria estéticas pós-modernas ditas poluídas e fragmentadas, com uma supermontagem, um imenso 
all over de imagens, sons e textos que se desdobram pelas diversas mídias. Assim, pode-se demonstrar que as possibilidades do fragmento e suas múltiplas recombinações, da montagem de imagem e som, favorecida pela estética pós-moderna encontram nos meios audiovisuais, ainda que de formas diferentes e específicas, um meio convidativo para sua absorção. Na televisão, essas possibilidades são aparentemente mais fortes. Primeiro, por ser um meio pós-moderno em um contexto pós-moderno que se faz presente nas residências ou nos espaços públicos de concentração de pessoas (bares, restaurantes, consultórios etc.), ambientes totalmente diferentes dos altares modernos, como o museu, e das salas de exibição, nos quais os sentidos estão confortavelmente acomodados para não desvirtuarem a atenção do que está sendo exibido. Segundo porque é um meio audiovisual favorável a aglutinar informação e significado, abertura de textos e popularidade.

Devido às inúmeras possibilidades de recombinação dos fragmentos, de agregar uma imagem moderna e uma pós-moderna, refletindo contradições e correspondências, as vinhetas institucionais interprogramas, ou seja, as vinhetas em computação gráfica de poucos segundos que veiculam o logotipo ou símbolo da emissora de televisão, revelam um objeto de definição menos evidente. Ao serem investigadas, porém, oferecem outras nuances sobre a relação entre o olhar do espectador e as imagens televisivas. Partese aqui do princípio de que um dos pontos fortes da análise das vinhetas é a quebra de referencial do espectador, ou seja, como essas metaimagens conseguem criar indefinições e dificuldades de compreensão para quem as vê, seja por meio de uma vinheta que aparenta ser uma série, um programa ou um comercial - como algumas da $\mathrm{MTV}^{2}$ - , seja pela maneira como o espectador é posicionado entre a câmera virtual e o objeto filmado, desconstruindo a noção de referencialidade desse objeto com relação ao espectador - como se observa em algumas vinhetas da Rede Globo. Desse modo, tornou-se importante entender como se modificou o referencial das vinhetas de televisão com relação à imagem na pintura, para compreender suas semelhanças e diferenças.

Ao fixar o observador e a fonte da imagem (uma parede, um painel ou uma tela de televisão), seguindo uma mesma linha para o interior da tela, simulando um eixo $\mathrm{Z}$ e uma consequente profundidade, é possível observar quais são os limites da imagem, ou seja, até que
2. Para maiores detalhes, ver: MUANIS, F. As metaimagens na televisão contemporânea: Rede Globo, MTV e suas vinhetas. UFMG, 2010 (mimeo.). 
ponto ela se encontra dentro da sua superfície de observação e até que ponto ela transborda dessa superfície. Ao transbordar, a relação com o seu observador também muda e, nesse sentido, uma análise final das vinhetas em comparação às imagens da pintura torna-se significativa, para provar que as vinhetas e a televisão estão inseridas no sistema da imagem, reproduzindo mudanças e operando em sua transformação. É importante ressaltar, contudo, que não se propõe aqui qualquer hierarquia entre a imagem televisiva e a pintura. A análise que se segue apenas indica as diferentes relações entre o olhar e a imagem, entre o deslocamento do olhar no eixo $\mathrm{Z}$ e a indução da profundidade, como elementos variantes no decorrer do tempo nos dois meios.

\section{Pintura, superfície e profundidade}

Ao considerar a posição que a imagem ocupou em uma superfície, desde que o homem começou a representar por meio da pintura, a imagem se deslocou pelo eixo Z. Entre o século V e o XIV, através da arte bizantina, da românica e da gótica, a imagem figurava em um mesmo plano, sem explorar uma perspectiva ou qualquer profundidade ilusória na superfície em que fora pintada. Também não havia nenhum volume ou qualquer ilusão de tridimensionalidade simulada pela utilização de relações entre luz e sombra. O olhar coloca o observador da imagem diante de uma imagem, que é representada em algum plano, paralela à superfície que foi pintada. A visão se desloca apenas lateralmente pela imagem.

Tal construção é observada em inúmeras pinturas, afrescos e iluminuras, como em O sepultamento de Cristo (c.1250-1300) (Fig. 1), em que os personagens em torno do Cristo deitado e seus seguidores estão amontoados praticamente no mesmo plano, contra um fundo amarelo. Nesse momento, não existe uma construção de profundidade mais elaborada, ainda que em seguida Giotto começasse a criar diferenças e imprimir uma maior "ilusão de profundidade numa superfície plana” (Gombrich, 2009, p. 201).

Do final da Idade Média até meados do século XIX, o olhar se deslocou da frente para o fundo da tela, devido à representação da profundidade. A imagem ganha uma complexidade crescente nesse tempo através da perspectiva e do volume, este representado por uma variedade cada vez maior de cores, luz e sombras, que geram 
diferentes tons. Com isso, o espaço da imagem se amplia, já que o olhar do observador se desloca de um ponto posterior à superfície da tela para o fundo dela, percorrendo um eixo Z, e para suas laterais. Seu olhar, contudo, fica atrelado à imagem.

A iluminação por zonas, tão comum no cinema com o intuito de gerar diferentes planos de profundidade, já podia ser observada nas pinturas barrocas e nas fontes de luz que realçavam a perspectiva e a profundidade. É possível identificar esse novo registro de olhar nos trabalhos de inúmeros artistas, como Caravaggio e Rembrandt (Fig. 2). A imagem chapada, que ocupa apenas um plano, já não atende às demandas do olhar da arte da época, que busca o fundo da tela como espaço do eixo de ação.
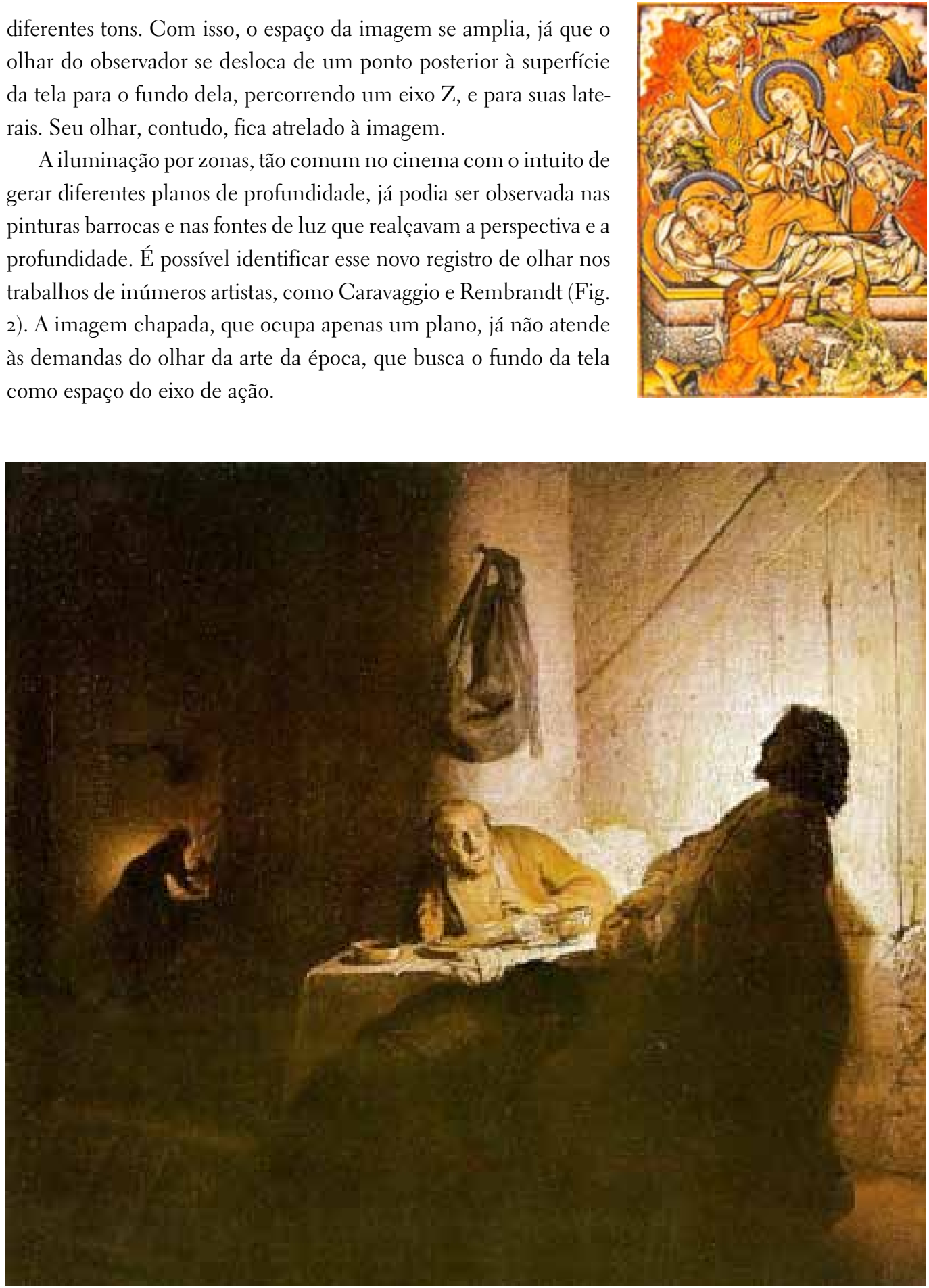
Figura 1. (ao lado, à esquerda)

Saltério manuscrito de Bonmont: O sepultamento de Cristo, c. 1250-1300

3. Em curso de pós-graduação na UFMG, ministrado em outubro de 2006 .

Figura 2. (ao lado, à esquerda) Supper at Emaus. Rembrandt, 1628

Figura 3. (ao lado, à direita) Le chemin de fer, Manet, 1872-73
De acordo com Oliver Fahle3 , o olhar sai para o campo do visível no impressionismo a partir das composições de Edouard Manet. Em algumas de suas pinturas, como em Le chemin de fer (1872-73), Manet pinta uma mulher que olha na direção do observador da pintura, ou seja, para algo que está fora da imagem que só ela estaria vendo (Fig. 3). Diferentemente de alguém que posa para um artista, ela estava lendo (o livro aberto em seu colo denota isso), e algo fora da imagem teria chamado a sua atenção. Ao seu lado, uma menina de costas olha da direita para esquerda por entre uma grade, em direção ao fundo do quadro. Para o que ela olha também não está representado na imagem. As duas personagens lançam, com seus olhares, vetores para fora da imagem, abrindo-a, para que o observador a transcenda para um possível contexto com a qual essa imagem se relaciona, ou seja, com o exterior dela. Apesar de não estarem representados dentro dos limites da imagem pintada por Manet, esses vetores levam o olhar do observador do quadro para o seu exterior, para uma imagem não representada, mas ainda assim visível.

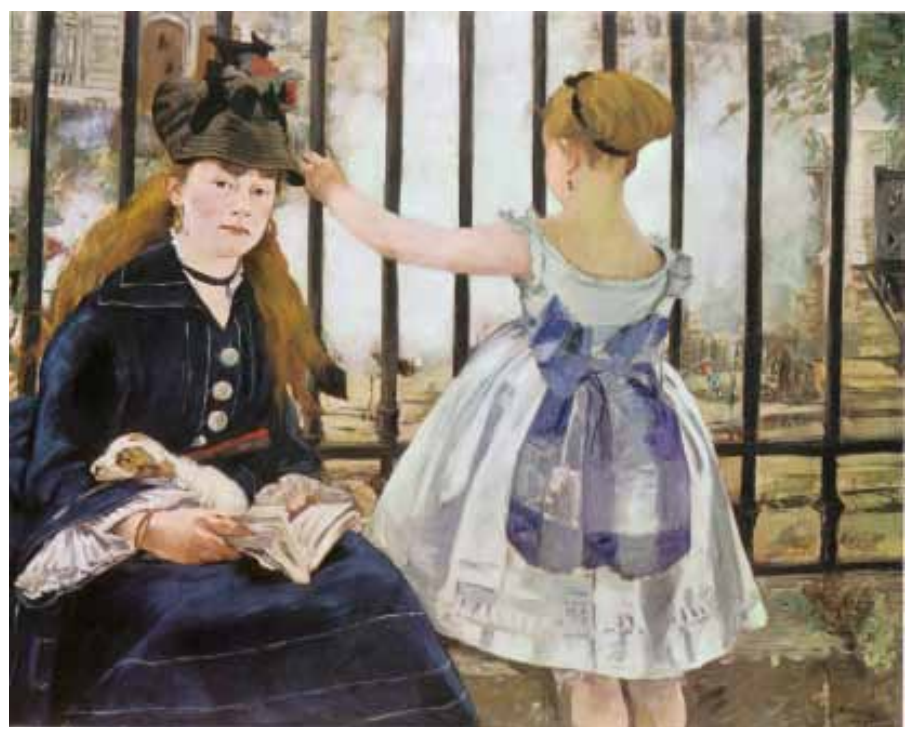

É com Cézanne, contudo, que o olhar do observador romperia os limites da superfície e da imagem pelo uso da cor, pela busca da natureza através de formas geométricas, priorizando seus volumes, em vez de uma reprodução realista, e pelas pequenas alterações na linha da perspectiva, obrigando o observador a uma reorganização 
de seu olhar. Ou seja, o olhar complementaria a imagem enquadrada, transbordaria da tela, e transcenderia para o visível:

Ele reúne duas concepções do visual. Por um lado, a clássica, na qual a imagem é figurativa, espacial e limitada. Por outro, a moderna, na qual a imagem é não figurativa, temporal e ilimitada. Antes de Cézanne, a imagem era a instância dominante que trazia o visível como algo exterior para a imagem. Após Cézanne, em todas as correntes da pintura abstrata, por exemplo, o próprio conjunto de relações múltiplas do visivel é parte da imagem. Nesse sentido, Cézanne se encontra numa virada não apenas da pintura moderna mas também na evolução da imagem (Fahle, 2006, p. 197).

Cézanne inicia o movimento de retorno à forma e à autorreferência da imagem. Ele faz a transição do impressionismo para a arte moderna, equilibrando forma e representação, significado e conteúdo. Oliver Fahle considera que, a partir de Cézanne, a pintura não se restringe à imagem que está estampada na tela. Ao contrário, a imagem na tela indica ao observador uma continuidade, para além dos limites do quadro, transcendendo a imagem para o seu exterior, e abrindo essa imagem para que o observador a complete. Giulio Carlo Argan reforça ainda que, para Cézanne, "a profundidade é una e contínua, e não uma perspectiva diante da qual se coloca o artista, numa contemplação que permanece exterior a ela, como um espectador de teatro" (Argan, 1996, p. 113), ou seja, a profundidade não se limita ao que está além da superfície, mas incorpora o que a transcende e extrapola seus limites. Assim, o conceito de visível, que é constituído pela soma da imagem com o que o observador vê além dos limites do quadro, torna-se preponderante sobre a imagem. Ao abrir a imagem, como afirma Fahle, Cézanne abre as portas também para a pintura moderna e para uma aproximação maior entre o observador e a pintura. Essa abertura e a ampliação do conceito de imagem para o conceito de visível, propostos por Fahle, são importantes para as conclusões acerca das vinhetas institucionais de televisão, conforme se verá mais à frente, já que o autor trabalha o conceito de visível permeando as diversas mídias imagéticas.

A arte moderna surge renegando a perspectiva e o realismo, privilegiando o sensorial. Com ela, a figura e a representação co- 


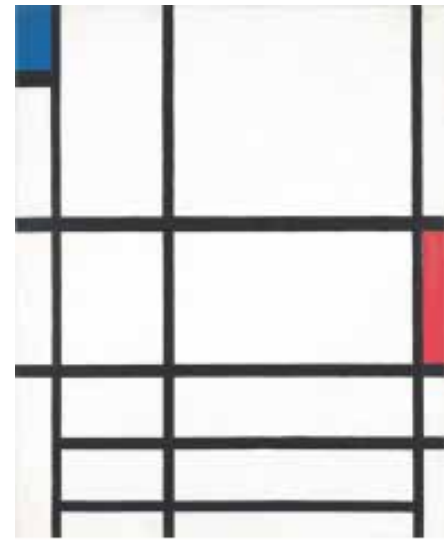

Figura 4. Composition en rouge, bleu et blanc II, Piet Mondrian, 1937

meçam, aos poucos, a se desconstruírem através de pinceladas rápidas, pontos coloridos, rabiscos e cores, até a figura se transformar em uma interpretação gráfica, em que o signo cada vez mais se afasta do seu significado. Com isso, a imagem sai novamente do fundo do quadro e se dirige à superfície da tela, evidenciando que a arte, além de romper com o figurativo, busca uma imagem que deve ser apreendida não pelo o que ela representa, mas pelo que ela é (Fig. 4). A diferença entre essa imagem e as pinturas medievais se baseia no apontamento para a exterioridade dela, pela abertura, liberando-se da representação e da composição que prendem o olhar do observador aos limites da superfície na qual se encontra a imagem. É nesse momento que a imagem volta a ser autorreferente, em que o que era visto como ornamental e periférico caminha para uma centralidade, rompendo com o monopólio da representação na pintura.

Com a pop art, algumas particularidades radicalizam os novos caminhos da imagem, que já buscava romper com o "planar'. Primeiro, os artistas da pop art começam a flertar com objetos industriais, retirados do cotidiano, que são adicionados ao quadro. Assim, o gesto que antes se limitava à pintura então se constituía também pelo ato de colar e de sobrepor, que invade o espaço de existência do espectador. Argan, citando a arte moderna, afirma que, "se a pintura pode ser um conjunto desordenado de manchas de cor e não comunica um significado, mas espera recebê-lo de quem a observa, não há por que deva estar num plano e ser feita a tinta." (1996, p. 575). Nesse sentido, as assemblages de Robert Rauschenberg e Jasper Johns eram exemplares: se, em um primeiro momento, papéis, cartões e objetos planos são colados na tela, em seguida, objetos de maiores dimensões são adicionados e pendurados, fazendo da tela apenas o espaço de onde a imagem, agora fisicamente tridimensional, brota em camadas (Fig. 5). A imagem passar a ser real e se materializa, volta a mover-se pelo eixo $\mathrm{Z}$, mas em sentido contrário: do fundo da tela em direção ao observador. A imagem planar, sem profundidade, não consegue satisfazer aos artistas e deter o movimento da imagem. Essa construção do planar - que irrompe a tela em uma grande colagem de imagens dialoga com alguns projetos gráficos executados por David Carson na década de 1980 e constitui uma característica importante das vinhetas da MTV. As colagens de Carson remetem diretamente 
às sobreposições da pop art, que reúne a invasão de imagens da publicidade, do cinema, dos jornais, da televisão, das revistas e dos outdoors; despersonificando-as.

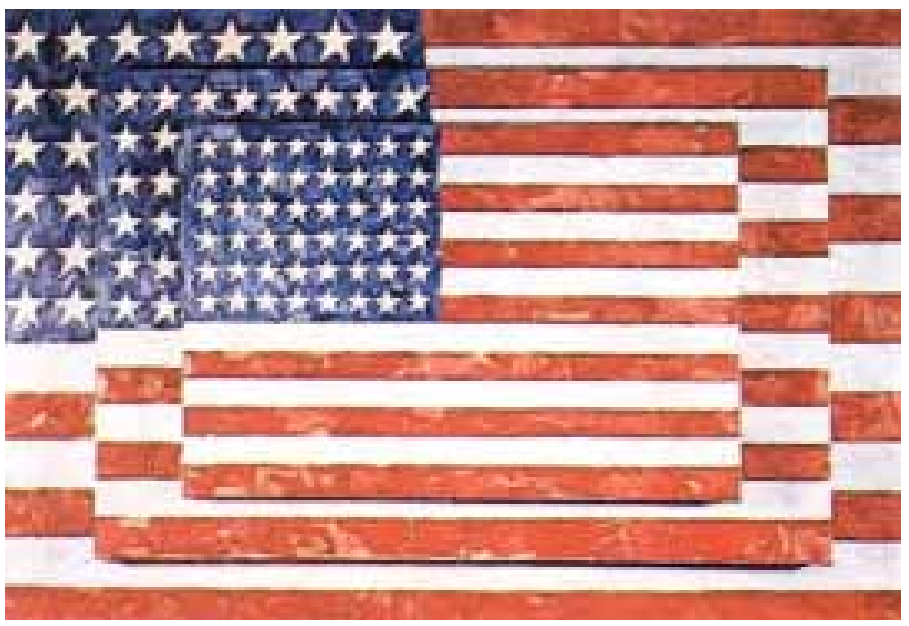

Por fim, ainda na pop art, nos happenings e posteriormente em algumas instalações atuais - e aí incluem-se também alguns trabalhos de videoarte - , as imagens envolvem o observador. Ou melhor, o observador adentra a instalação, preenchendo a imagem e, por que não, tomando parte dela. O observador agora vivencia a imagem, ampliando ainda mais os seus pontos de vista, já que ele pode olhar para vários lados e, por vezes, até mesmo, andar por dentro da obra. Por ser uma instalação, não se pode definir com precisão a superfície em que a imagem está, já que ela pode estar dispersa no espaço, como imagem para o observador. A partir das diversas possibilidades de realização de uma instalação ou de um happening, a noção de superfície não fica tão precisa como era uma tela.

Desse modo, a conclusão que se tira a partir do movimento que o olhar faz durante as diferentes épocas da pintura demonstra como a visão do pintor e a do seu observador exploram inicialmente o espaço dentro do quadro, partindo de uma composição em duas dimensões em um mesmo plano para outra que simula uma tridimensionalidade ao criar uma linha de perspectiva e definições de luz e sombra para alcançar uma profundidade. Em seguida, o olhar passa a buscar o que está fora da imagem, o visivel que pode complementar a imagem. Isso acontece inicialmente com a transi-
Figura 5. Three flags, Jasper Johns, 1958 
ção operada por Cézanne para a arte moderna, quando a imagem se libera da perspectiva e da precisão da composição e prioriza as formas. É o caminho que se faz para a imagem autorreferente, que resulta nas imagens abstratas modernas, não representativas e selvagens. A pop art, através de colagens e assemblages, supera a imagem planar abstrata e rompe a superfície da tela. Os happenings e as instalações que a partir de então começam a ser realizadas passam a envolver o observador, romper com a ideia de superfície e trabalhar o conceito de o observador fazer parte e entrar na obra.

Assim, pode-se observar uma transformação na imagem da pintura, ao longo da história, em que ela busca romper os limites do suporte quadro e da representação, indo do plano para o fundo do quadro, para em seguida voltar não representativa para o plano e, finalmente, sair do quadro e envolver seu observador. Nesse movimento, o resultado final para o este último é que seu olhar e ele próprio se aproximam cada vez mais da imagem - ou talvez seja a imagem que se aproxime deles. Essa aproximação se dá pelo fato de a imagem, cada vez mais aberta, demandar sua participação para fazer a conexão entre a imagem e o visível; bem como porque o suporte também se aproxima cada vez mais do observador, exigindo uma interação muitas vezes física. Desse modo, se conclui que a imagem clássica estaria mais fechada para o visível, enquanto a moderna seria mais aberta.

Para Fahle, existiria a relação entre imagem e visível independentemente da imagem na tela. O visível é fruto da junção entre o dispositivo técnico com a sua estética: esses fatores, combinados, permitem uma maior abertura, pelo fato de a imagem remeter à sua continuidade fora da superfície - o visível - apesar de ele não estar lá, de fato, em imagem. Ele existe apenas como uma ideia na cabeça do observador, que completa a imagem. Dessa maneira, na pintura, conforme visto anteriormente, o espaço do visível corresponde ao da imagem, quando a composição de Cézanne começa a dialogar com o "fora de quadro", fazendo com que o olhar do observador transcenda os limites da imagem no quadro e adentre no visível.

O trabalho de Oliver Fahle, contudo, propõe a relação entre imagem e visível não apenas na pintura, mas nas diferentes mídias imagéticas. Fahle lembra que tanto Foucault quanto Deleuze já apontavam o cinema como um lugar em que se poderia observar, assim como na pintura, o espaço do visível. Nesse sentido, tanto o som quanto o movimento favorecem a percepção do observador. $\mathrm{O}$ 
som, porque complementa a imagem que está na tela, levando o espectador para o "fora de quadro", abrindo a imagem para o visível. Por outro lado, qualquer movimento de câmera aponta para um vetor de exterioridade da imagem, já que o espectador, acompanhando esse movimento, completa por ele mesmo a imagem na superfície. Através de sua percepção do visível e do que entrará ou sairá de quadro em seguida, transformando-se em imagem, o espectador amplia sua percepção da imagem que estaria fora de quadro.

\section{Vinhetas de televisão}

Nas vinhetas da Rede Globo e da MTV, é possível perceber um movimento da imagem similar ao percurso feito pelo olhar do observador durante as diferentes fases da pintura. Nas vinhetas da Rede Globo de Televisão que compreendem o período entre 1965 até 1975 - da fundação até o início do uso da imagem sintética por Hans Donner -, predomina a imagem do logotipo na posição final da assinatura. Ela é planar, ocupa uma mesma linha de profundidade, porém, por meio do movimento de entrar ou sair de quadro, sua imagem transcende para o visível (Fig. 6).
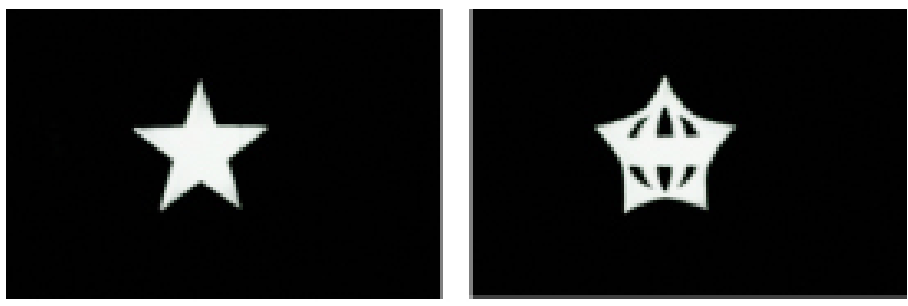

A partir de 1975, com a criação do novo logotipo da emissora, até o ano de 1984, com o uso da imagem sintética, ampliam-se as possibilidades de movimento das bolhas transparentes, das esferas metalizadas e das formas geométricas da emissora, combinando-se com um espectro de cores que tomam forma através de rastros de luz. Agora há um movimento mais consistente, com relação ao período anterior, e que vai ganhando complexidade. O movimento se dá lateralmente e sobre o eixo Z, em profundidade. À medida que a vinheta se torna mais complexa, seus objetos animados começam a entrar na imagem e sair dela pelas laterais e pelos cantos

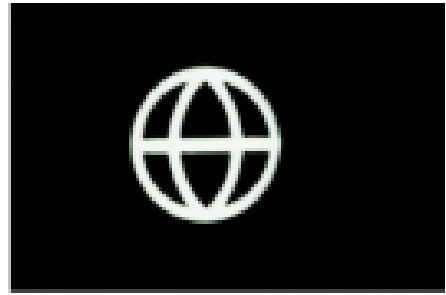

Figura 6. Vinheta da Rede Globo (1965) 
do quadro, transcendendo o olhar do observador - para o visível. É como se o visível, como uma continuidade da imagem (Fig. 7), passasse pelo espectador e se concretizasse em imagem na tela da televisão à sua frente.

De 1984 ao ano 2000, mais uma vez os recursos da computação gráfica, gerando uma imagem sintética livre de amarras, permitem um maior aprofundamento nas imagens das vinhetas. Agora, o observador passa a ser o centro da ação. O seu olhar se confunde com o da câmera, e ele entra na ação. Os referenciais de espaço, velocidade e tempo são completamente quebrados dentro das vinhetas, e o espectador penetra no logotipo, como demonstra a vinheta de 1989 .
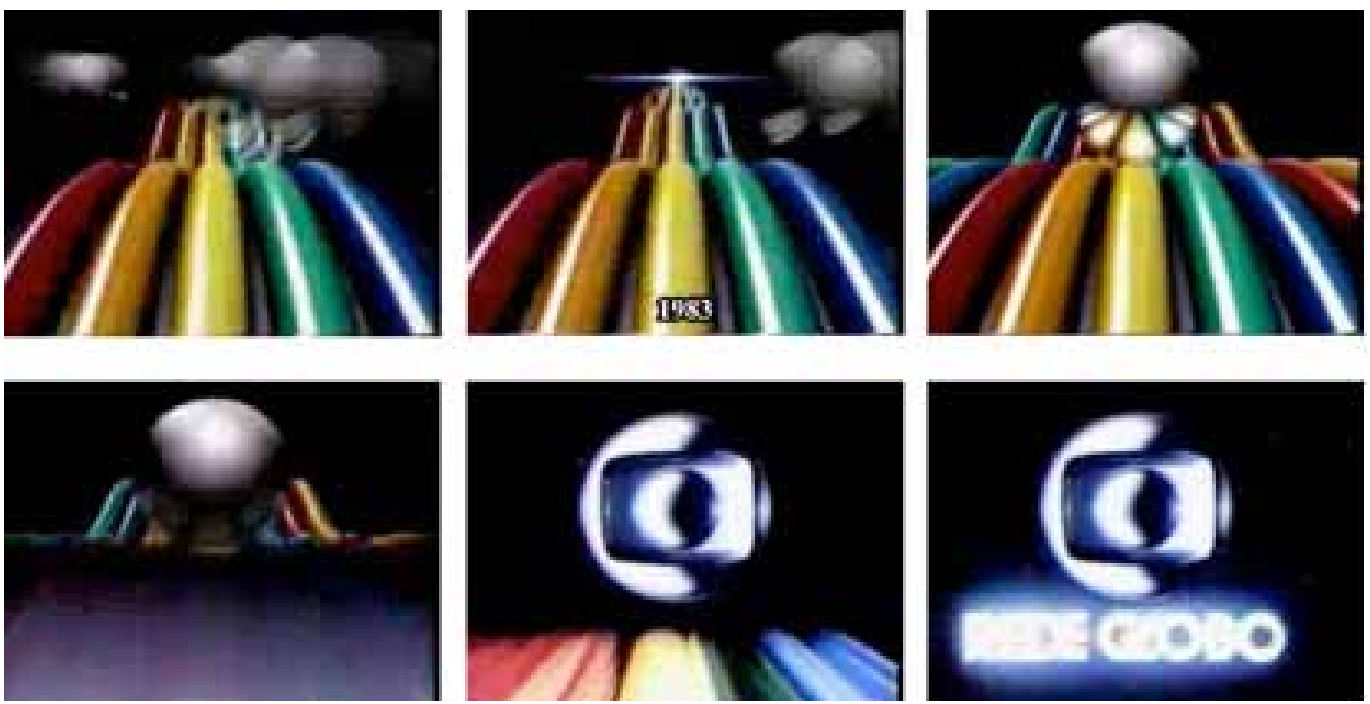

Figura 7. Vinhetas da Rede Globo

A imagem sai da tela para o campo do visível, que o engole (Fig. $(1983)$ 8). De uma forma similar, ainda que diferente, se consideramos o visível como um prolongamento complementar da imagem, a posição do observador em relação à imagem é muito parecida, ou seja, ele se encontra dentro dela. Pode-se considerar que, em uma instalação, ou happening, o suporte tela não está necessariamente presente e fica mais difuso ao redor do observador. Na televisão, o suporte tela continua o mesmo, com a imagem preenchendo o espaço dentro de sua moldura. 

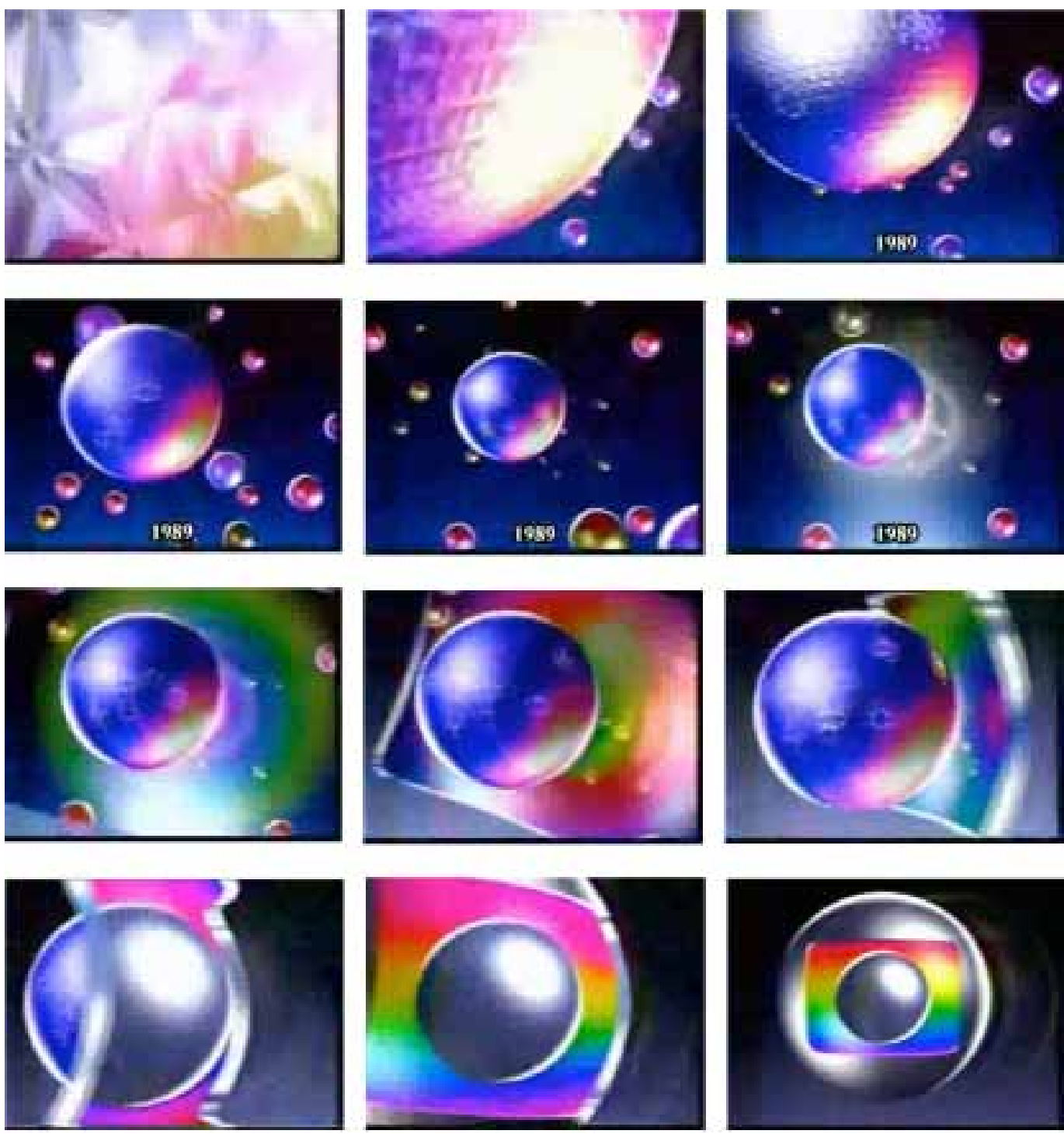

Contudo, da mesma maneira que o visível não é imagem, em uma instalação, os outros ângulos que não estão diante do camFigura 8. Vinhetas da Rede Globo (1989) po visual do observador também operam no campo do visível, necessitando que ele se movimente para transformá-lo em imagem e esta, anteriormente vista, em visível. A diferença nos dois casos, entre instalação e vinheta de televisão, é que, em grande parte das vezes, no primeiro caso, o observador tem o controle direcional do seu olhar, e, no segundo, o espectador continua 
sendo guiado pela imagem dentro da tela. Ele percebe o visível, mas não pode mudar de direção, não tem livre arbítrio sobre seus movimentos, buscando outros olhares. É possível, contudo, em um exercício de predição, que com a interatividade da televisão digital essa diferença se enfraqueça, na medida em que, assim como em um videogame em que esse tipo de sensação já é há muito experimentada - em jogos como Doom, Wolfenstein, entre outros - , o espectador possa controlar o seu percurso e o seu olhar por dentro do ambiente de uma vinheta. Ainda assim, essa sensação já pode ser experimentada até mesmo com uma estética similar a das vinhetas da Rede Globo, em que proliferam esferas em movimento, dentro da cúpula de um planetário com um teto côncavo, que favorece a simulação de um infinito, o movimento de planetas e astros.

O mesmo ocorre com a MTV. Como já nasce em um período de televisualidade, que agrega todas as possibilidades imagéticas, a MTV, ainda que usando poéticas distintas de emissoras como a Globo, também utiliza esses diferentes registros de movimento da imagem e do olhar do espectador. Isso acontece até mesmo pelo fato de a MTV ter como definição de sua poética justamente a

Figura 9. MTV Hijack, Precursor, mistura e a variedade de diversas outras.

Londres, MTV London
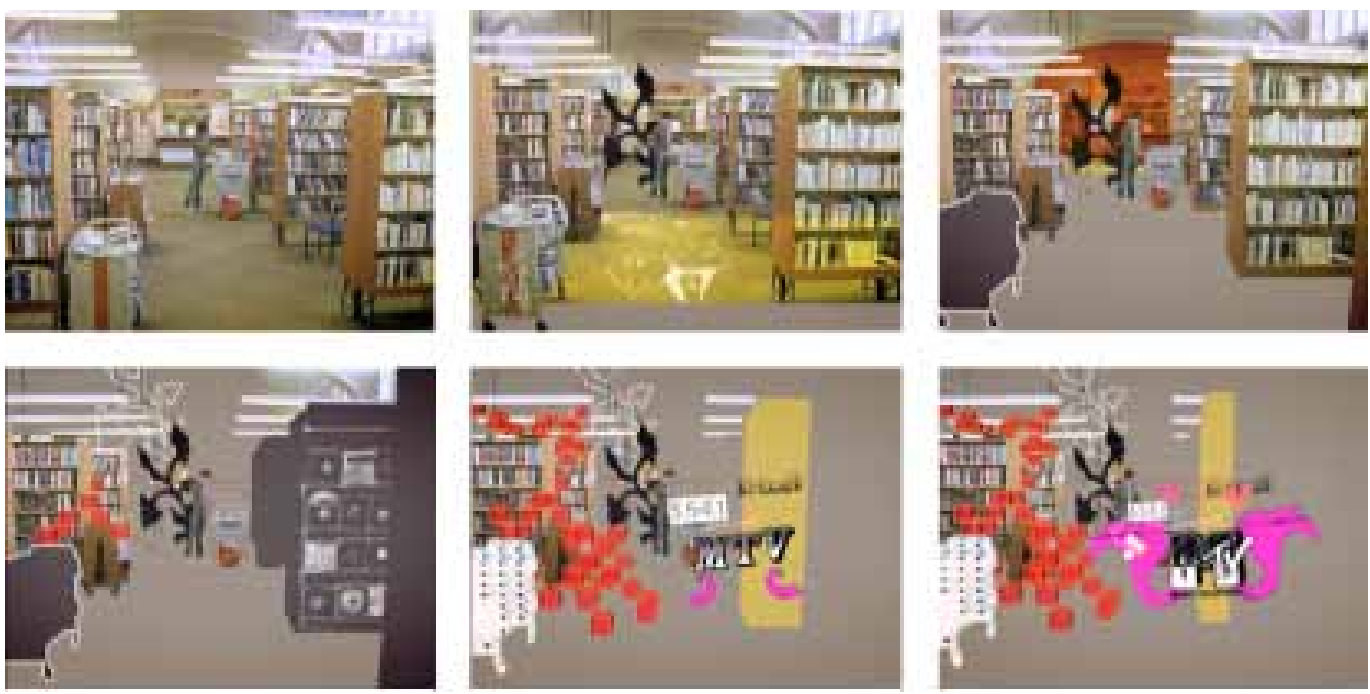
À MTV talvez se deva acrescentar uma forma de visualidade tributária das assemblages da pop art e das colagens pós-modernas de David Carson, na qual a sobreposição de imagens dentro da tela, apesar de não poder reproduzir os movimentos concretos de colagem que transcendem a superfície - feitos por Jasper Johns com a sobreposição de elementos - , parece transcender a tela, emergindo dela em direção ao espectador e ao visível (Fig. 9).

Em meio à cacofonia de imagens trocadas a todo momento nas vinhetas da MTV, o resultado é uma imagem abstrata, formada por vários signos, que, deslocados de sua função e, muitas vezes sem ligação entre eles, perdem seu significado particular, transformando-se em algo novo, ocupando uma tessitura de imagens que é apreendida pelo observador não de maneira paleo, mas neotelevisiva.

\section{Considerações finais}

Apesar de retirado do cinema - o que não compromete a argumentação, já que parte dessa discussão sobre a imagem é similar no cinema e na televisão - , um exemplo em que essa sobreposição parece emergir da tela é o filme A última tempestade (1991),

Figura 10. A última tempestade, Peter Greenaway, 1991 de Peter Greenaway.

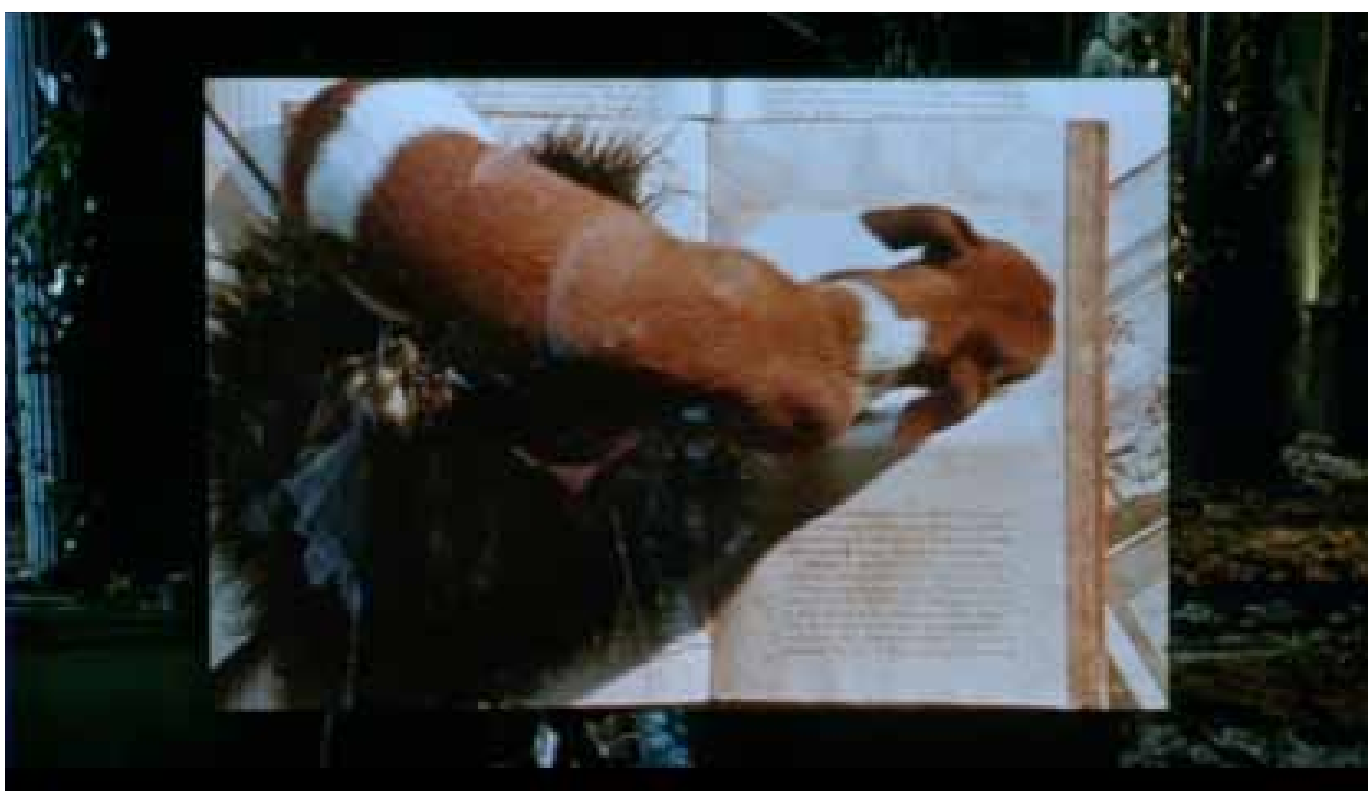


Tomando uma cena como exemplo, depois de uma sucessão de colagens sobrepostas, que compõe uma imagem do filme, o cineasta quebra totalmente o referencial do espectador, quando, por cima da imagem interna, surge um cachorro: ele atravessa o quadro, visto de cima, mudando o referencial do espectador com relação às imagens até então apresentadas e abrindo ainda mais a imagem para o visível (Fig. 10). Peter Greenaway trabalha com as novas tecnologias do vídeo de alta definição associadas ao cinema. Tanto no som quanto na imagem, ele trabalha com a colagem e as incrustações. As vozes de todos os personagens do filme são a voz de Prospero, o protagonista interpretado por John Gielgud. A voz de um personagem é sobreposta a ela mesma em uma assemblage de vozes, às vezes com uma modulação diferente e com outra voz por trás, o que lhes confere identidade e diferenciação na fala de um personagem para outro. É como se Peter Greenaway fizesse com o som a mesma operação que Abel Gance fazia com as imagens em suas múltiplas fusões em Napoleón (1927). O filme de Gance e sua linguagem de fusões impressionistas, telas múltiplas e temporalidades distintas é, inclusive, citado por Greenaway em entrevista a Maria Dora Mourão, como ideias que "não tiveram seguidores no momento", mas que agora "podem ser retomadas, (...) depois de um interlúdio de quarenta ou cinquenta anos" (2004, p. 182), justamente pelas possibilidades que as novas tecnologias proporcionam. Greenaway chega a uma forma arrojada, comparável só mesmo aos experimentos audiovisuais conceituais; seja nas operações das vanguardas de 1920, já citadas aqui; seja nas experimentações audiovisuais dos últimos 30 anos. Muitas dessas operações são vistas hoje em videoclipes e vinhetas da MTV.

Pode-se também traçar relação entre os movimentos audiovisuais nas vinhetas da Rede Globo e alguns trabalhos de Oskar Fischinger. Os movimentos e de formas geométricas sob um eixo $\mathrm{Z}$, denotando uma profundidade em uma imagem verdadeiramente bidimensional, que eram experimentados por Fischinger e divulgados em circuitos de públicos restritos na década de 1920, hoje são vistos nas vinhetas da Rede Globo, em um contexto totalmente diferente, por um público muito maior, além de estabelecer um alto poder de comunicação - ainda que esta seja em função do símbolo e da música da emissora, demarcando e pontuando a grade. O que Greenaway afirmou sobre a incapacidade, à 
época, de o público entender e de a técnica facilitar a difusão das inovações de Abel Gance em Napoleón, foi formulado por Wassily Kandinsky 40 anos antes e é válido também para a relação que se pode esboçar entre os filmes de Oskar Fischinger e as vinhetas da Rede Globo.

De acordo com Kandinsky, o espiritual na arte se traduz por um triângulo de constante movimento para cima, em que o artista inovador do passado, posicionado solitariamente no pico do triângulo, tem suas ideias absorvidas no futuro pela sua base, dialogando, com o tempo e em progressão geométrica, com um universo cada vez mais populoso. Para o pintor, "é esse pão que seus artistas lhe oferecem e é desse pão que, amanhã, quando ocupar o seu lugar, a camada seguinte, por seu turno, se nutrirá" (2000, p. 36).

Nesse sentido, a imagem sintética e a mudança que está em curso, em que se prioriza a experiência sensível das imagens, podem aplicar-se tanto às experimentações do cinema quanto às vinhetas de televisão. Louise Poissant contribui com elementos que corroboram a guinada imagética:

A era da simulação indica ainda que a relação com os símbolos muda. Os signos não estão mais lá para designar o mundo das coisas, um real autônomo e exterior aos signos. Ao contrário, a simulação estende sua influência outorgando-lhe dimensões que não estão presentes nos sinais arbitrários e abstratos (linguísticos ou matemáticos) e imprimindo algumas propriedades do mundo das coisas e da experiência sensível. Assim, ela consagra a necessidade de conjugar pensamento e sensibilidade. (...) não se está mais diante do velho sonho de manejar o mundo ou as coisas através de signos, mas antes de tomar resolutamente o partido de manipular os signos como coisas, de construir mundos simbólicos (Poissant, 1997, p. 90).

A era da simulação proposta pela autora, reforçada pelas possibilidades da imagem sintética, amplia também a discussão sobre o visível, proposta por Oliver Fahle. Abordar o visível é importante, nesse caso, pela necessidade de validar as metaimagens televisivas. $\mathrm{O}$ visível abre a imagem de Manet e da pintura moderna, assim como a imagem das vinhetas de televisão aqui analisadas, que reproduzem, guardadas as devidas proporções, uma relação de olhar e proximidade entre imagem e espectador muito próxima à da pintura. 
Comprova-se, assim, como a imagem televisiva dialoga claramente com um sistema mais amplo da imagem. Relações essas que também podem ser vistas desde os filmes de Fischinger até o trabalho de Peter Greenaway, citado anteriormente, entre tantos outros.

Em função da imagem eletrônica e das novas possibilidades trazidas pela imagem sintética, a televisão aumenta ainda mais a tendência ao visível porque nela são possíveis muito mais mudanças na imagem do que no cinema. Não é à toa que hoje o próprio cinema, principalmente o dos chamados blockbusters, faz uso dessa imagem sintética para alcançar outras formas de visualidade. $\mathrm{O}$ visível seria, portanto, mais pertinente ainda na televisão: a paleotelevisão, com uma perspectiva de fechar mais, e a neotelevisão, baseada em uma televisualidade e nas imagens autorreferentes. Esta última abriria ainda mais do que a primeira. Assim a televisão é mais favorável à transição do olhar do espectador para o visível, ainda que o cinema também realize essa operação.

Tais relações tornam-se evidentes na televisão, não apenas através da análise de suas vinhetas institucionais, mas também ao percebermos uma transição da imagem televisiva, tomando a teoria de John Caldwell como ponto de partida. Parte-se da imagem de "intensidade zero" da paleotelevisão, chapada, com pouca profundidade, para a imagem cinemática com contrastes e profundidade, característica da televisualidade típica do período neotelevisivo. Hoje, essa imagem sai da superfície não apenas pelo movimento em direção ao visível, mas pelo aumento e pela utilização comercial dos televisores com imagem 3 D. Esse caminho objetivo da transformação da imagem no percurso histórico da televisão, claramente observado atualmente, reforça a relação lógica entre um dos aspectos da transformação da imagem na pintura, que coincide com mudanças específicas na imagem da televisão.

Assim, fica claro como a transformação da imagem na televisão segue caminhos similares e ao mesmo tempo complementares aos de alguns aspectos da pintura, o que demonstra a necessidade não apenas de estudá-la como um campo de imagens variadas, em que é possível encontrar desde narrativas fechadas até narrativas abertas e não narrativas, representativas ou não representativas, mas também de considerar que as metaimagens e, no caso aqui estudado, as vinhetas, podem ser pensadas na sua relação com as transformações da imagem de um modo mais amplo. 


\section{Bibliografia}

ARGAN, G. C. Arte moderna. São Paulo: Companhia das Letras, 1996.

CALDWELL, J. T. Televisuality: style, crisis, and authority in

American television. New Jersey: Rutgers, 1995.

CARONE, M. Metáfora e montagem. São Paulo: Perspectiva, 1974.

FAHLE, O. "Estética da televisão. Escritos sobre uma teoria das imagens televisivas". In: GUIMARÃES, C.; LEAL, B. S.;

MENDOZA C. C. (Org.). Comunicação e experiência estética. Belo Horizonte: UFMG, 2006.

Jenseits des Bildes: poetik des französischen.

Films der zwanziger Jahre. Weimar: Bender, 2000.

GOMBRICH, E. H. A história da arte. Rio de Janeiro: LTC, 2009.

KANDINSKY, W. Do espiritual na arte. São Paulo:

Martins Fontes, 2000.

KLANTEN, R.; MEYER, B.; JOFRÉ, C. (Ed.).

On air: the visual messages and global language of MTV.

Berlin: Die Gestalten Verlag, 2005.

MOURÃO, M. D. "Entrevista: cinema e novas tecnologias.

Conversa com Peter Greenaway". In: MACIEL, M. E.

(Org.). O cinema enciclopédico de Peter Greenaway.

São Paulo: Unimarco, 2004.

MUANIS, F. As metaimagens na televisão contemporânea:

as vinhetas da Rede Globo e MTV. Tese (doutorado).

Belo Horizonte: UFMG, 2010.

POISSANT, L. "Estas imagens em busca de identidade".

In: DOMINGUES, D. (Org.). A arte no século XXI:

a humanização das tecnologias. São Paulo: Unesp, 1997. 